\title{
Crossing Boundaries Between School and Work During Apprenticeships
}

\author{
Sanne F. Akkerman • Arthur Bakker
}

Received: 20 May 2011 / Accepted: 27 November 2011 /

Published online: 14 December 2011

(C) The Author(s) 2011. This article is published with open access at Springerlink.com

\begin{abstract}
In vocational education, there is an ongoing discussion about problems occurring in school-work transitions and in relating school and work-based learning processes. Apprenticeships have been identified as valuable learning and working trajectories for making successful transitions and relations between school and work. However, they have been mostly located as activities taking place solely in the workplace with hardly any attention for what students do and learn during release days at school. Deploying the theoretical notion of boundary crossing, we conducted a study in Dutch senior secondary vocational laboratory education, investigating the actions and interactions taking place between school and work during apprenticeships, taking into account both the cognitive and identity-related challenge of students' boundary crossing. Specifically, we conducted workplace visits and analyzed how apprentices' experiences at work are discussed and reflected upon with students and teachers at school. The findings reveal that what students are expected to learn in work practices is largely rendered invisible by the technologymediated, scripted and socially distributed nature of their work. They are educated as lab technicians doing much manual work, but become more operators of machines in the workplace. The release days seem to provide initial ways to explicate and reflect with the teacher on what is going on in work, but they can be exploited more fully for vocational learning. Based on the results we discuss how school and work institutions can mutually feed each other in facilitating apprentices' learning.
\end{abstract}

Keywords Apprenticeship · Boundary crossing $\cdot$ Release days $\cdot$ School-work transition $\cdot$ Vocational education $\cdot$ Work placement

S. F. Akkerman • A. Bakker

Freudenthal Institute for Science and Mathematics Education, Utrecht University, Utrecht, The Netherlands

S. F. Akkerman $(\bowtie)$

Department of Education, Faculty of Social and Behavioural Sciences, Utrecht University, Heidelberglaan 8, 3508 TC Utrecht, The Netherlands

e-mail: s.f.akkerman@uu.nl 
An ongoing discussion in vocational education examines how students can be supported in making successful transitions from school to work. Much of this discussion has departed from a 'comparative' approach, involving concern about differences between school and work practices and about the gap that exists between job requirements and educational programs, nationally but also internationally (e.g., Biemans et al. 2004; Detmar and De Vries 2009; Finch et al. 2007; Toolsema and Nijhof 2003). What seems to ground a comparative approach is a focus on transfer and the idea that similarity between school and work sites is the most preferable for successful transitions to work.

Instead, some scholars have started to take a 'relational' approach toward the school-work discussion, considering how relations between both sites can be established despite the differences existing between them (e.g., Guile and Griffiths 2001; Onstenk and Janmaat 2006; Poortman 2007). This latter approach seems to rest on a notion of boundary crossing as an alternative to transfer (Tuomi-Gröhn et al. 2003) and an interest in productive interactions that take place between practices. Particularly in light of the relational approach, apprenticeships have been rediscovered as workplace learning trajectories that are theoretically interesting as a way to overcome boundaries between school and work.

Organizing one or more apprenticeships during the formal educational trajectory (students in work placement) seems in line with situated learning theories (Brown et al. 1989; Lave and Wenger 1991). Following an apprenticeship model of learning, students can learn through a process of observation and gradual participation. Billett (2001) points out that the value of learning through work resides not only in the ability to engage in everyday work activities through which capacities can be reinforced, refined and transformed, but also by the possibility to receive direct guidance from coworkers, and indirect guidance through clues and cues provided in the workplace.

Despite the value attributed to apprenticeships, empirical studies revealed that apprenticeships do not necessarily fulfill this boundary crossing function. Hardy and Parent (2003) found that education is not always integrated in work environments. Billett (2010) argued that work activities and interactions also have their limitations including the risk of weak, incomplete or uninformed learning as well as reluctant or unavailable co-workers. As observed by Detmar and De Vries (2009), workplaces are not necessarily selected for apprenticeships because of the learning opportunities they offer. Besides, Onstenk and Janmaat (2006) found that there is often little use of workplace learning experiences in school settings.

Though the relational approach has led to a renewed interest in and study of apprenticeships in vocational education, the learning and working processes during apprenticeships have been studied mostly at work, considering for example how work activities, relations and interactions with colleagues or supervisors, either facilitate or hamper learning. We argue, however, that this does not fully capture the route taken by students as they, at least in most of Dutch senior secondary vocational education (MBO) and in several other countries, also go back to school during apprenticeships, where they talk to other students and teachers about their work experiences. In this study we investigate in more detail the actions and interactions at both school and work during apprenticeships. This will allow us to consider how school and work are related and how they can mutually contribute to learning processes during apprenticeships. 
In the next section we elaborate on our conceptual framework of boundary crossing, pointing out how this relational approach differs from the comparative approach and the notion of transfer. We also identify two types of challenges that are relevant to be studied, leading us to our central research questions.

\section{Crossing Boundaries in Vocational Learning}

Over the last decade problems in school-work transitions have often been conceptualized in terms of boundaries (Harreveld and Singh 2009; Konkola et al. 2007; Tanggaard 2007; Tuomi-Gröhn et al. 2003). Based on a review of 181 studies on boundary crossing and boundary objects we have defined a boundary in the realm of social life as "a sociocultural difference leading to discontinuity in action or interaction" (Akkerman and Bakker 2011a, p. 133). In terms of this definition, school and work can be seen as constituting distinct practices, with different aims (schooling and working) and with different cultural and local histories. These differences can lead to discontinuities for the student, as they may require him or her to shift in role, perspective, or type of expertise to draw on, when moving from school to work or vice versa. Simultaneously, however, the concept of boundary suggests some sameness and some continuity in the sense that two or more sites are relevant to one another in a particular way. In the case of the school-work boundary, both sites constitute a frame of sameness based on a shared interest in the development of future professionals, as the student may experience for example in the aims and assignments that are formulated for the apprentice and that both teachers and workplace supervisors agreed upon.

When problems in school-work transitions are conceived as boundaries, establishing a productive relation between school and work practices can be conceived as a matter of boundary crossing. Boundary crossing is a concept that has been proposed as an enriched notion of transfer (Tuomi-Gröhn et al. 2003), but differs from transfer in various ways. First of all, whereas transfer is mostly about one-time and one-directional transitions, primarily affecting an individual who moves from a context of learning (e.g., school) to one of application (e.g., work), the notion of boundary crossing includes ongoing, two-sided actions and interactions between practices (Säljö 2003). Second, whereas transfer emphasizes the need for similarity between practices, boundary crossing is about finding productive ways of relating intersecting dissimilar practices.

What is relevant is that both these notions lead to different foci in understanding school-work problems. Transfer leads to questions about the correctness of the school curriculum, that is, whether it includes the proper equipment for students to work, and to questions about whether students can recall and apply what they learned at school when they are at work. Of course such questions are relevant and have resulted in large scale attempts to (re)investigate the knowledge and skills needed at work. In Dutch vocational education this has led to qualification files describing required competences at work which have been introduced as standards for each educational program. In contrast to transfer, however, the notion of boundary crossing urges us to consider not only how schools prepare for students' future work practices, but simultaneously how current work experiences of students 
during school trajectories are exploited for learning to become a professional. Consequently, work is not to be seen as a context outside the educational practice, but as part of the schooling process. Thinking about boundary crossing leads to questions about how and to what extent continuity is maintained despite sociocultural differences between school institutes and local workplaces.

Two different types of sociocultural differences can be expected in learning processes at the school-work interface. First of all, one can expect a difference in epistemic culture, meaning that school and work are culturally and historically developed practices with a specific attitude toward knowledge and knowledge claims (Knorr-Cetina 1999). As mentioned earlier, scholars have found that school practices often rely on more abstract and disciplinary knowledge claims, whereas work practices often rely on more applied, implicit and practical knowledge claims (Lave 1988; Nunes et al. 1993; Smith 1999). From a boundary-crossing perspective then, the challenge is to find a way to interrelate these different types of epistemologies in favor of the learning process of the apprentice (Guile and Griffiths 2001).

Scholars focusing on boundaries and boundary crossing have come to stress how school and work not only represent different epistemic cultures but call on different identity positions. Apprentices find themselves in an ambiguous position, being a student and novice who is learning, yet at the same time a professional who is expected to know and act (Akkerman and Meijer 2011). In the context of trade vocation, Tanggaard (2007) characterizes apprentices' position as that of marginal strangers "who sort of belong and sort of don't" (p. 460). Accordingly, as we have described elsewhere in more detail (Akkerman and Bakker 2011a), students are at the periphery of both practices and face simultaneously a neither/nor and a both/and situation of belonging to communities. This ambiguous position can lead to insecurity, but also creates the potential to act as a broker, meaning that one can introduce elements of one practice into another (cf. Wenger 1998).

From a boundary-crossing perspective, we want to consider in more detail the movement of students during apprenticeships, specifically in the domain of Dutch senior secondary vocational education (MBO). As in several other countries, Dutch senior secondary vocational education has experienced a recent innovation toward competence-based education. Competence-based education comprises models of education in which not academic disciplines, but competencies needed for employment and society are taken as the basis for curriculum development (Grant et al. 1979). Compared to other countries in which vocational students are often educated locally within companies (e.g., USA, UK, Australia) or within educational institutes (France, Sweden, Finland), the Dutch system of senior vocational education is based on a mixed model (Nelen et al. 2010): there is a public system of educational institutes following national qualifications defined for each occupation, though with a large influence of social partners in the labor market. In line with this, apprenticeships are a central part of the schooling system, particularly in the last 2 years of the educational trajectory.

Considering the route taken by students entails investigating not only their work experiences, but also their experiences when coming back to school. The central questions in this study are: 1) what differences in epistemic cultures and identity positions do apprentices encounter between the school and work practices they engage in during their apprenticeship? And 2) how is continuity promoted in the 
actions and interactions between workplaces and school? Based on the results we discuss how school and workplace can mutually facilitate apprentices' learning.

\section{Data Collection and Analysis}

After a broader exploration of senior vocational education in the Netherlands (e.g., Bakker et al. 2011b), we conducted a more detailed study in laboratory education at the fourth level (vocational education in the Netherlands consists of four levels of qualification; the fourth level gives entry to higher professional education). We focused on a group of ten apprentices in a Dutch vocational school during the final school year of a four-year program; these students in work placement received a small allowance from the companies where they worked. The final school year comprises two apprenticeships lasting 5 months each. This group was coached by two teachers at school who were responsible for the organization of the students' apprenticeships and for communication with workplace supervisors. During the school year, the two teachers organized bi-monthly release days in which the apprentices returned to school to present and discuss their work experiences with other students and with teachers.

Our data collection consisted of several sources. We observed and video-taped four subsequent release days of the group of lab apprentices over a six-month period. We conducted interviews with the two teachers after each of these meetings, asking them how they experienced the meeting, the individual students, their presentations, and how they considered the apprenticeships of the different students. We wrote an observation report for each release day. Based on information-oriented sampling (Yin 2009), we selected four students (two male, two female) for a more detailed study. Their workplaces represent a typical variety of laboratories for which lab education prepares its students: Jenny and Simon (all pseudonyms) worked in clinical labs (in hospitals, mainly routine work), Aron in a research lab (mainly nonroutine work) and Melissa in an industrial chemical lab (mixed routine and nonroutine due to a large variety of products).

Each of the four students was interviewed twice for about $1 \mathrm{~h}$ on how they experienced school and work practices. Visits to their workplaces were organized, lasting between 2 and $4 \mathrm{~h}$. During the workplace visits we observed the nature of the work and the student's role in the workplace. Unfortunately, we were not allowed to record any ongoing interactions between supervisors and apprentices due to the possibility of details about patients and chemical products being discussed. We also interviewed the workplace supervisors, asking for their general perceptions of the apprentices' progress in learning and working, about their approach in supervision, and their perception of the school and apprenticeships more broadly. During these workplace visits, we also made photographs and collected artifacts that represented the nature of the work being done (e.g., graphs, data, tables, organization schemes, standard operating procedures, competence checklists). For each workplace visit an observation report was written in the form of a thick description (Guba 1981). All interviews were transcribed verbatim.

To analyze our data we first scrutinized all data about the workplaces in which the four apprentices worked, including our thick descriptions and the interviews with 
students and workplace supervisors. This allowed us to distill the cognitive nature of the work and the identity position of the apprentice in this practice and determine how this contrasts with lab education (research question 1). Three categories of the cognitive nature of the work emerged from the data through a process of inductive coding (Denzin and Lincoln 2000). Second, we considered the observation reports and videos of the release days, analyzing the interactions between the students and teachers regarding 1) the way in which the epistemic cultures of school and work are interrelated and 2) the way in which the students are positioned in the discourse. In addition, we analyzed the interviews of various actors to determine the actions and interactions that were generated by the release days (e.g., the preparation of the presentations by the students at work). The analysis of the release days and school-work interactions entailed iteratively going through all data. This allowed us to determine how continuity was maintained in three different ways (research question 2).

The next sections report on the main findings of these two steps of analysis. To illustrate the findings, we have included several excerpts from interviews and interactions of the release days. By means of triangulation we have ensured that the claims are consistent with what was found throughout the data sources.

\section{The Workplaces: The Epistemic Nature of the Lab Work and Position of the Apprentices}

Our observations of the workplaces revealed three central characteristics of the laboratory work, consistent across the four workplaces, that are relevant for understanding some of the differences in epistemic cultures and identity positions between school and work (research question 1). First of all, the work laboratories all relied strongly on technology to conduct chemical tests and measurements. Walking through the laboratories one could see a multitude of (computerized) machinery. Figure 1 shows a typical example of the work: an employee runs a series of measurements in the spectrophotometer and studies the output produced by the machine and computer program. As explained by the apprentices and workplace supervisors, a lab technician's work (including the work of the apprentice) is often physically organized around one or a few machines (e.g., as shown in Fig. 1 on the left, a spectrophotometer, connected to a computer).

The cognitive work consisted mainly of preparing biomedical or chemical samples so concentrations of particular substances can be measured, setting up the machine for tests on those samples and interpreting the test outcomes that are generated. More elaborate explanations of this interpretative activity by students and workplace supervisors revealed that the computer often facilitates the specific interpretation of graphics and numbers, for example indicating when outcomes are not as expected or not within predefined limits (e.g., within a limit of two standard deviations, see Fig. 2).

A second characteristic of the lab work that we observed was the extensive presence of scripts, often in the form of so-called "standard operating procedures" or "SOPs" in short. The SOPs were used as guiding principles for processes of decision-making, defining what steps to take when and in what case (based on 
Fig. 1 Working with a modern measurement machine connected to a computer

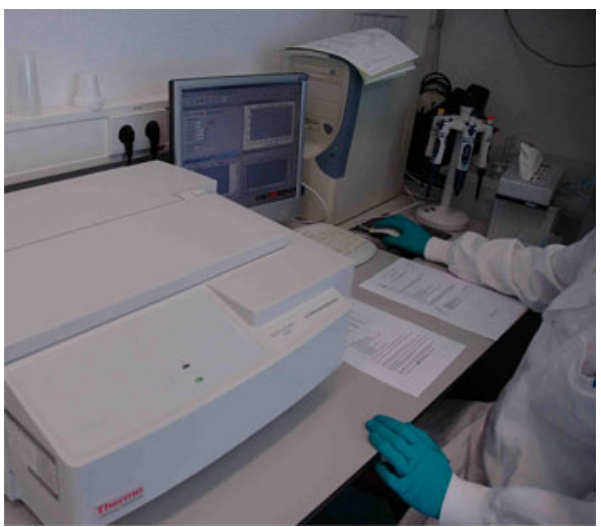

certain standards for outcomes). The SOPs were often kept on shelves just above or beside the working spaces. SOPs were especially prominent in quality control labs and companies that adopted GMP (Good Manufacturing Practices).

A third characteristic that we observed was the role of the social system in the lab work. When asking apprentices and workplace supervisors for example how they used the output for final interpretations and decision-making, they described how, most of the time, more than one person was involved. In the case of routine work, forms were filled in by lab technicians but always signed by an authorized colleague. In cases where results were not as expected and appeared strange, it was necessary to consult the local authority leading the shift to interpret this and determine what should be done next (e.g., running an extra test to make sure that the machine was calibrated well).

Based on these three observations the nature of the work in the observed laboratories can be described as technology-mediated, scripted and what Hutchins (1995) has called socially distributed cognitive systems. A result of this nature is the implicitness, but also fragmentation of the work. The cognitive processes taking place at labs simply extend beyond any individual lab technician; they include calculation methods and standards embedded in the machines, but also as predefined in scripts and bits of expertise from various workers. Moreover, the way things are done differs between labs.

We highlight a few differences that students experienced in terms of technology, scripts and the social system. Several workplace supervisors, teachers and students

Fig. 2 Test results shown on computer screen. The downward trend indicates that the chemical substance has to be replaced: its concentration is not stable anymore

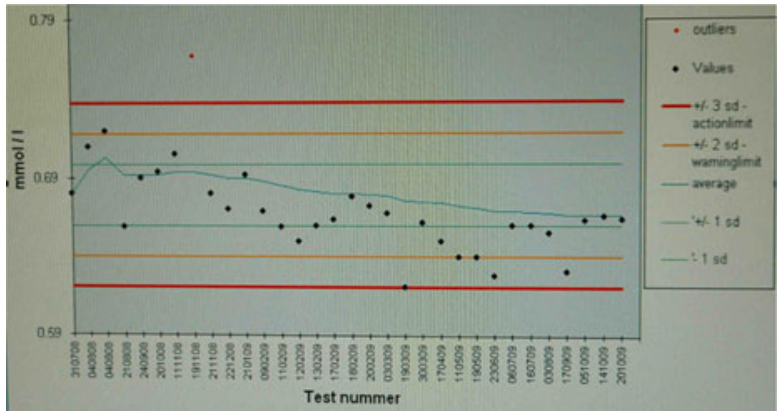


worded the main difference between lab education and laboratories in terms of being educated as a technician versus having to work as an operator of machines. They also explained that schools were not capable to buy and incorporate the newest technology used in labs. Consequently, some students mentioned that they worked on machines that were new to them. Jenny, for example, reported that mass spectrophotometry is the main technique she used at work, but at school only two lessons had been devoted to it. "I think this is too little, because almost every lab nowadays has mass spectrophotometers - most companies work with them." A teacher confirmed that these machines have changed the profession considerably.

With regard to the scripted nature of work, we observed that the routine nature of work in many labs (except research labs and industrial labs with many different products) appears in contrast with what students experience at school. At school students are not used to routine work, because they keep learning new techniques. At work, they sometimes reported finding routine work boring.

Differences between school and work in terms of the social distribution of work were reflected in several comments made by the students in the interviews. On the one hand, workplace practices were considered more complex than at school. This students' perception is expressed for example by Aron by stressing how a particular topic reported in his work proved more complicated than he had learned at school:

So I now know that it can all be less simple than I have learned at school... If someone would ask me again to determine the reproducibility, I would do it in the way that is common in the specific workplace. Or, if the company appears not to have any standard method, I would choose to use the formula I learned at school, but make sure that I explicitly mention this in a report.

On the other hand, the students also reported in various comments to experience workplace norms as clearer and more compelling than school norms. For example, Melissa claimed that she found it easier at work than at school to judge if analyses were correct because at work she felt there were more opportunities to compare results with previous findings or with those of other labs. So whereas work is experienced by students as more complex because it does not necessarily follow the standardized lines of disciplinary reasoning learned at school, work is simultaneously experienced as more simple than school, because of the local knowing that guides the students in conducting the lab work.

It may be tempting to draw from the above that school is educating more disciplinary details than actually necessary for the technology-mediated, scripted and distributed nature of the cognitive work in laboratories. Such a conclusion, however, is not consistent with the opinions of teachers and workplace supervisors. Both teachers and supervisors stated in the interviews that vocational students are expected to move beyond knowing that (e.g., recognizing that a measurement value falls outside a control limit). They should also learn how and particularly why things are being done the way they are (e.g., how certain calculations are conducted, why the decision is taken to conduct a specific test again). It is argued that this is necessary in order to make justifiable interpretations and decisions. The two teachers we interviewed stressed several times that students should know what precisely machines are doing for them and why. These expectancies of what vocational 
students as future lab technicians should know stand in contrast with what the nature of the work during the apprenticeships allows them to learn. Technology, scripts and other lab technicians 'take over' much of the work, thus for a large part render invisible the what, how and why that is expected to be learned.

Considering the identity position of apprentices, we observed that all apprentices are accepted as participants in the working system, doing work that needs to be done and rarely work that is 'invented' for them. This allows them to learn the work as it occurs naturally, though it differs per workplace and apprentice whether they are considered to participate as a worker or as a learner. In general, their participation is peripheral in the sense that they engage mainly in routine work related to one particular machine or they conduct a specifically designed individual project to be graded at school. Nevertheless, the apprentices all indicated in the interviews to appreciate doing work that is "for real" and of benefit to a larger goal (e.g., patients' health, production of highquality products, making money). As explained by both apprentices and workplace supervisors, apprentices are responsible for reporting results and making some preliminary interpretations, but these are always checked by others. One reason given for this is that there is often too much at stake to leave it up to a single lab technician, and this is particularly true for apprentices. In chemical labs, there are often entire production processes that are dependent on the interpretations and decisions being made. In biomedical and clinical labs one small mistake in calculations can have direct implications for the amount of medicine prescribed to a patient. What is implicit in this argumentation is that apprentices are expected to make more mistakes and that they still have to learn.

The way the interactions at work are described in the interviews indicated that it acceptable for apprentices to ask questions. Apprentices denote that they not only turn to supervisors but also to co-workers (who are often close at hand) when they encounter something that they do not know. Workplace supervisors' comments, however, indicate that such questions are more about what needs to be done than about understanding. One workplace supervisor from the research lab described how most apprentices could learn more: "I definitely think Aron needs to open his mind more on the 'why' to explain the 'how.' So he can try to think for himself. And he and other students have a great potential to improve this!" Several workplace supervisors also described how they saw apprentices develop toward a "grown-up" and professional lab technician during the apprenticeship. Melissa was even offered a job during her apprenticeship.

\section{The Release Days: Going Back to School}

During the apprenticeships the group of students also visited their school every 2 months to present and discuss their work experiences with the teachers and other students. The teachers and workplace supervisors reported some telephone and email contact regarding the initial placement of the student and a midterm visit by the teacher to the workplace. They indicated that, if no problems arose with the student, no interactions between them took place. These release days are of particular interest 
as windows for understanding how the students' school and work participations are being related, both regarding cognitive and identity work. We want to present some fragments of interaction we observed during the release days as well as reflections on them from students, teachers and workplace supervisors. This data indicates how continuity in actions and interactions between school and work is promoted (research question 2).

In the observed group of vocational students, the release days were organized in the form of exchanges of work experiences between students and teachers. Each meeting started with a round robin on how things went in the students' workplaces; subsequently some practical issues were discussed. Then two students were asked to give a PowerPoint presentation about their workplace and the nature of their work (30 $\mathrm{min})$. These presentations were followed by questions $(15 \mathrm{~min})$. Some students also attended courses to prepare for higher professional education ( $\mathrm{HBO}$ at a bachelor level).

The assignment to present about their work and workplace at school generates actions and interactions at work. The students pointed out in the interviews that the presentations require some preparation in that they needed to gather information about the workplace (e.g., the type of organization, the details about a chemical liquid, or about the work done by a machine), including issues that the students do not have immediately available from their apprenticeship experiences (e.g., how a ligand, a particular chemical substance, binds iron). This means that the students have to use various information sources to construct a satisfactory image of their workplace to communicate to others. Students we interviewed indicated, for example, to have asked a teacher or the workplace supervisor about something or to have searched for information on Wikipedia. Aron described how he had prepared his presentation very seriously and in close collaboration with his workplace supervisor:

\section{Fragment 1 - Interview with Aron}

Aron I have, we mostly worked on the presentation to make sure that you [I], let's say, don't make mistakes in what you say. Because that's what I, what I notice at work is that, when you say something that does not really make sense, then they [workplace colleagues] are so sharp on this. Whereas, in that sense, they are much sharper than a teacher. They, like for example 'total ligand'. My supervisor at work thought I should not use it [the term 'total ligand'], because the samples we are measuring are filtered, so you do not have a total anymore.

Researcher But... so you showed your supervisor your presentation then?

Aron $\quad$ Yes. And we have, at least with my supervisor, I put the slides together and for the boss we actually, I gave the presentation and then he said: "OK, if you have to give this at school, then just talk about the total, because otherwise, because if the total is not the total and you speak of an even smaller part then the matter becomes too complicated for, well, for people who don't know anything about it."

Researcher Aha. So you simplified it so that you could present it here.

Aron Yes. Well, I already thought of this, I do it in this way, but if they don't give permission to do so, then, well then you really cannot. 
What is interesting is that this particular student Aron indicates that he learned a lot from preparing his presentation as it led him to consider his work during the apprenticeship in more detail. The workplace supervisor said the following about the way he helped Aron to prepare his presentation:

He [Aron] liked the way I taught him to express difficult things in his own words and stuff. I told him to explain it with a metaphor, to be the specific subject [here a ligand]... and then telling him: you are a ligand, and now what?

What would you do to get food [in this case iron]?

Most of the students seemed to have well prepared PowerPoint presentations, often starting with background information about the organization and the workplace, and then going into the details of the work they had been doing. Some students wrote down their lines beforehand to support themselves during their presentation. The following fragment is from Jenny's presentation and exemplifies how the presentations typically started:

\section{Fragment 2 - Presentation by Jenny}

Jenny [1] Well, welcome at my presentation. I will, have been doing an apprenticeship at [name of hospital lab]. And will now tell something more about that. First, I am going to address the organization and then tell about the work I do. And then about my research assignment, which will be a reaccreditation...

[2] Well, on that slide you saw a picture of a LC-MS/MS [a particular type of mass spectrophotometer] that I have worked on mostly during this period. And below here, those two pictures, is what well, naturally, what you see if the LC-MS/MS is running. Well, once it has run, one can see the results. The picture at the right shows, that one shows, let's say the qualbrowser, well thus, the qualitative analysis. So then you go and see: what is in my sample? And then the most right picture, no, the most left I mean, that is well, the software to see the results so to say, you can, have the computer itself calculate the concentrations by means of the calibration standard, that you include as well. And that will be shown in such a program, in the quanbrowser, so the quantitative analysis. And then it also really calculates the precise concentration. And then, you go and check every measurement, check whether the peaks are nice and whether they, whether the, the program picks the right peak and of the checks are within the deviations of 15 percent. If you have done that, you can print it and get the picture below and than a report is printed listing all the measurements....

[3] Well, then the application forms can be filled in, and once that is filled in, a colleague from the lab, because I am an apprentice I am not allowed to input, so then there needs to be a formal signature of someone from the, from the laboratory. Once that is done, I can just, by means of the right picture, there you fill in the sample number, because every sample goes with a number, and there you can just fill in the sample number and the result. And naturally, we have also just included the checks and those are filled in a digital check card. And there you input the values that you found and then it puts it automatically in the digital check card. 
The technology-mediated, scripted and distributed nature of the laboratory work that we observed in the workplaces was clearly reflected in Jenny's subsequent description (utterance [2] of Fragment 2). When introducing her work, Jenny immediately referred to the machine that she had been working on, indicating that one of her tasks was to read and check the results produced by the computer. The immediately following quote (utterance [3] of Fragment 2) hints at the scripted and socially distributed nature of the work. Here she describes how measurement standards are indicated on the prints on the basis of which she can fill in forms, and describes how these forms have to be checked and signed by others. The routine or implicit nature of 'knowing' in this system can be seen in her frequent use of the word 'naturally', when describing the sequence of her actions.

Besides illustrating the cognitive nature of the work, the presentations of the ten students reveal how they position themselves, talking about 'their' work, workplace, and machine. Sometimes they show some hesitance regarding this position, as can be seen for example in Jenny's shift between 'we' and 'the lab' in one sentence, accompanied by what we interpreted as an apologetic smile: "No this is really...Well yes, we receive, let's say, the lab [smile] receives many samples." We interpret this as a shift from presenting herself as an employee to presenting herself as one of the students. Generally, though, the apprentices refer to themselves as part of the lab, for example saying: "No, that we don't do that at the lab". By positioning themselves within the lab, they present themselves as experts informing others about a specific workplace. This expert positioning is visible also in the way in which some students used visualizations and metaphors to explain to others how certain operational processes work. For example, Jenny included a demo that is being used at her workplace to introduce people to the LC-MS machine. As cited earlier, Aron referred to a person who wants food as a metaphor for a ligand that needs iron in order to explain a chemical process to the students. These instances show how presenters assumed the other students to be novices who have to be informed about the work, not necessarily in a complete and detailed, but in a comprehensible way.

The interactions following the presentations of the students mainly took the form of question-answer interactions. Noteworthy is that students and teachers posed different types of questions. The students often asked about specifics of the work and workplace, for example about the machine, routine work, the time pressure or the atmosphere at work, but also about options to get further qualifications at a higher professional level. Students frequently made comments from which we inferred that they considered modern machines appealing and were less interested in routine work than in research or carrying out a variety of analyses. Those who did not like routine work often expressed an interest in moving on to higher professional education (HBO, leading to a bachelor degree). Atmosphere at work was also regarded as important. At school students were used to see each other regularly and chat amongst themselves about topics they cared about. A typical comment about the atmosphere at work was: "I like it at here [at her workplace]. It is nice, with a lot of young people. The atmosphere is really good. A bit like at school." However, one student made jokes about the colleagues who were all older than 40 and only talked about their newest caravan. He liked teasing his older colleagues with stories about his and his peers' drinking behavior-thus positioning himself somewhat outside the community of employees. The interviews with students show that they value each 
others' presentations mostly for the information they get about the workplace allowing them to evaluate whether they would want to work there or at a similar type of laboratory.

However, the students turned out to have different individual orientations in this evaluation process. Whereas some students were focused on continuing education and therefore interested in the various responsibilities of vocational and higher educated lab technicians, other students were concerned with the variety of measurements one is conducting at a workplace or about the societal relevance of the work. Simon, for example, frequently asked about opportunities to get higher qualifications and the nonroutine nature of work, whereas Melissa was more oriented toward what she thought was important: "I think health is very important. I want to fight diseases."

Whereas students' questions were directed at specifics of the workplaces, teachers' questions mostly addressed disciplinary issues underlying the work that students presented. Typically, the teachers asked the students to ground knowledge claims in more scientific terms. For example, when Jenny talked in her presentation about 'nice peaks', one teacher picked up on this:

\section{Fragment 3 - Questions after Jenny's presentation}

\begin{tabular}{|c|c|}
\hline $\begin{array}{l}\text { Richard } \\
\text { (teacher) }\end{array}$ & Yes, OK. \\
\hline Richard & What are nice peaks? \\
\hline Jenny & $\begin{array}{l}\text { Yes. } \\
\quad[\text { laughter }]\end{array}$ \\
\hline Jenny & $\begin{array}{l}\text { What are nice peaks? Yes, that... Well, I just } \\
\text { those that are perfectly straight. }\end{array}$ \\
\hline Richard & Is that a nice peak? That one isn't it? \\
\hline Jenny & $\begin{array}{l}\text { Well, well, that is the funny thing a } \\
\text { spectrophotometer]. Look, these are just } \\
\text { overlapping. So with the MS/MS you can just, } \\
\text { chromatogram that is overlapping... because } \\
\text { measures just in a split second the one compor } \\
\text { component and then the internal standard. And } \\
\text { say subsequently, due to which, here it measure } \\
\text { doesn't. And there, on top of these, yes the little } \\
\text { makes the peak. }\end{array}$ \\
\hline Richard & Well, the question was what is a nice peak? \\
\hline Jenny & Yes. \\
\hline Richard & Could you draw one? \\
\hline Jenny & [laughter] I cannot draw it. \\
\hline
\end{tabular}

The two teachers (Paul and Richard) explained to us after Jenny's presentation that they indeed wanted to see from these presentations whether students knew what they should know, particularly because they work with machines:

\section{Fragment 4 - Teachers' reflections on presentations}

Paul Yes, in a way it is too easy, like, I just put it in the machine and it will come out and we will see. One can expect something more like "Oh, it is like this". You have to know what the machine is doing for you. What is it 
really doing? What does it calculate? If you do not know that, then yes well, then mathematical knowledge is not needed at all. Just do it.

Richard Yes, because what happens. Simon said "I did not know, I will ask my supervisor." But what do you think that happens, that if you do not question what it does, then how do you know that the computer is doing the right things?

Paul Yes, like nice peaks. What are nice peaks?

Richard Yes, indeed. [citing Jenny:] "Very straight." [role-playing as if talking to her:] "What do you mean, a peak cannot be straight, can it?"

Researcher But, what is a nice peak? Just for my own understanding?

Paul Well, nicely stretched, no tailing, no fronting.

Richard It has to be symmetrical.

Paul Yes, symmetrical of course.

Researcher And so you do expect them to know this, that they know an answer to these questions?

Paul Yes, of course. They have to know this.

When we asked students how they experienced their presentation and the interactions following it, they all showed some disappointment. When Aron elaborated on this disappointment in the interview he argued that the presentations during the release days primarily have a function for the teacher to check whether or not the student really understands the mathematical, chemical or biomedical aspects of the work. He stated that the questions asked during the presentations by other students are often superficial and that the teachers often bothered him with details that were not necessarily relevant in terms of knowledge needed in the workplace.

It seems that the disappointment experienced by students is not only a matter of whether or not the knowledge claims asked about by teachers are relevant, but also of having different foci in the interactions. Whereas teachers were focusing on the cognitive aspects of work, students seemed to be doing important identity work. The presenter is in a way narrating to others "who am I in this workplace?" and other students reported to listen to a presentation asking themselves, "would that workplace be interesting and suitable for me in my future as professional?" With such questions in the back of their minds, questions from teachers to elicit the underlying 'how' and 'why' of the cognitive work can easily be taken by students as "testing questions" that reposition them as students rather than professionals in statu nascendi.

Though students show some disappointment about the questions asked after their presentations, we found a few instances in which these questions did lead them to ask for more information at work. For example, Aron's supervisor mentioned in the interview that, back at work Aron had told him that he had received one question about a molecule that he could not answer. This illustrates how students sometimes connected school and work, in this case by taking questions raised during the release days back to work.

\section{Promoting Continuity in Vocational Learning}

From a boundary-crossing perspective, the aim of this study was to consider the learning movements of apprentices during apprenticeships by studying both work 
experiences and release days at school. The central questions in this study are: 1) what differences in epistemic cultures and identity positions do apprentices encounter between the school and work practices they engage in during their apprenticeship? And 2) to what extent is continuity promoted in the actions and interactions between workplaces and school?

Regarding the first question, we can conclude that the vocational school and the workplaces we have visited show important epistemic differences. We found that the lab work is technology-mediated, scripted and socially distributed, implying that knowing and knowledge claims are implicit in a socio-technical system and exceed the cognition of any individual lab technician. This is in contrast with the more explicit knowledge (e.g., being able to conduct calculations, or to carry out analysis alone) that is focused on in lab education. One of the ten students interviewed referred to the school-work difference as being educated as a lab technician (learning to do the manual work) versus having to work as an operator (operating machines). Teachers and supervisors confirmed that much of the work that lab technicians eventually do is in between what the qualification files of lab technician and allround operating technician demand. Yet it is well possible that the manual work with relatively old machines at school is good preparation for the more automatic work in workplaces with the newest machines - this is at least what several teachers in other settings told us (Bakker et al. 2011b).

Regarding the identity positions, we found that 'the students' are accepted as peripheral participants in the workplaces. Their participation is peripheral in the sense that they engage mainly in routine work related to one particular machine, but also because their interpretations and decisions are often checked by others. They are coached on knowledge and skills mostly during regular interactions with workplace supervisors and colleagues on the spot, and several workplace supervisors report some growth during the apprenticeships. Yet, in line with teachers, workplace supervisors emphasize that they expect apprentices, more than is currently the case, to know not only what to do, but to also know how and why certain lab processes take place.

The sociocultural differences in epistemic cultures and identity positions of students between school and work indicate a paradox. Whereas students are expected to learn in practice not only what to do, but how and why things need to be done in a certain way, the nature of the work does not allow them to learn this naturally. Tailor's apprentices as described by Lave (2011) seem to learn from observing, but in the laboratory context the how and why is largely rendered invisible by the technology-mediated, scripted and socially distributed nature of work (cf. Hoyles et al. 2010; Hutchins 1995). Taking an educational perspective, one can interpret much of the lab work as being a black box. For Latour (1999), a machine can become a black box for the user when this machine acts as one piece: "when many elements are made to act as one, that is what I will now call a black box." (p. 131). He characterized black-boxing as:

the way scientific and technical work is made invisible by its own success. When a machine runs efficiently, when a matter of fact is settled, one need focus only on its inputs and outputs and not on its internal complexity. Thus, paradoxically, the more science and technology succeed, the more opaque and obscure they become. (p. 304). 
In line with this, Billett and Rose (1997) found that workers who had acquired their skills through everyday practice often comment that they learned how things are done, but not why they are done in a particular way. When holding on to the expectations of diverse stakeholders about what vocational lab technicians should know, the cognitive challenge in learning about lab work then is to make these processes visible for discussion and reflection. Bakker et al. (2006) have pointed out the importance of making the invisible visible for learning and improving work and they have suggested ways of doing so in different companies (Bakker et al. 2009, 2011a).

For our second question about the way in which continuity is promoted between school and work, we analyzed how apprentices' experiences at work are discussed in bi-monthly release days at school. Also, we considered reflections on the release days from students, teachers and workplace supervisors. We found how release days promote continuity in several ways. First of all, the presentations during release days trigger students to think about their work and workplace, and search for additional information not immediately available from the apprenticeships. Such information helps to bridge the communication across school and work settings. Second, we found how students show pride and take on an expert position by talking about "my workplace" and "my work" and trying to explain things to other students in a comprehensible way (e.g., by using visualizations and metaphors, often offered by their workplace supervisors). This finding is consistent with the observation of Fillietaz et al. (2010) that analogical discourse can function as a conceptual resource for teaching and learning in technical vocational work and education. Third, we saw how in the interactions after the presentations, teachers posed questions that call for more specific explanation of the how and why of the processes described by the students during their presentations. Doing so, the teachers seemed to ask for elicitation of processes that are partly invisible in the work. An example of this was the teachers asking why an element in a graph is a nice peak. Though the teachers' questions can be seen as initial instances toward 'opening up the black box' of laboratory work, we did not observe much elaboration in this direction during the meetings. This lack of elaboration can be understood as the students described the teachers' questions as "testing questions" that are not necessarily relevant. This is in line with Wedege's (1999) observation that vocational students can be skeptical about the relevance of theoretical disciplines (in her case mathematics) in their vocational education, as their learning perspective is focused on the vocational qualification rather than on learning mathematics. In light of the aforementioned pride and expert positioning one can understand that students felt disappointed about the interactions when they had the idea they were being tested. However, we also found one instance in which a student took up a question and took it back to work.

To conclude, we argue that the observed release days seem to establish some continuity between school and work as they enable discussion of and reflection on these work experiences and generate new school-work interactions such as information gathering at work for the school presentations and passing on questions received from students and teachers. Yet, there also seems more to gain in exploiting release days for crossing the school-work boundary. In terms of relating the epistemic cultures of school and work, the release days could focus more explicitly on opening the black box that is created by the technology-mediated, scripted and 
distributed system of knowledge working, and by doing this shed more light on the how and why of core processes in laboratory work. The questions that teachers posed about underlying calculations seemed to be intended for this, but were perceived by students as testing questions. A first step is thus to make clear that why and how questions are relevant, for example by framing them as a collaborative process of getting a better understanding of black-box processes in lab work. Furthermore, students can be stimulated more explicitly in passing on the questions they receive and discuss during release days to the workplace, using them as vehicles for further learning during the interactions they have with colleagues and having a legitimate reason to bother supervisors with questions. The importance for students to ask questions at work in order to learn was also mentioned by workplace supervisors in the field of life sciences of Dutch secondary VET (Wesselink et al. 2010). What should be taken into account in this respect is the aspect of empowerment, in the sense that release days can provide students with an informed and legitimate reason for asking more questions. Related to this is also what Edwards (2011, p. 33) refers to as relational agency, which is "based on confident engagement with the knowledge that underpins one's own specialist practice, as well as a capacity to recognize and respond to what others might offer in local systems of distributed expertise."

In terms of identity work, release days can allow more for discussing and comparing students' positions and future orientations in finding work that suits them than is currently the case. Students' different orientations in evaluating (future) work and their own position toward work are worthwhile to exchange, as it may give students new ideas about possible criteria, but also inform them on how they are unique as beginning professionals. For teachers the challenge is to find a balance in focusing on cognitive and identity work, and to be aware that questions that are cognitively oriented (e.g., asking what one means with a nice peak) may also have an effect in terms of positioning (suggesting they are still students who need to be tested).

For exploiting better the potential of apprenticeships in terms of crossing schoolwork boundaries, several important suggestions have already been made in the literature. Griffiths and Guile (2003) argued for developing students' polycontextual and connectivity skills so that students are better able to work and learn in different contexts. Billett (2010) suggested three kinds of interventions: developing and enacting a workplace 'learning curriculum', enacting guided learning strategies in the workplace, and engaging workers in a critical reflection upon workplace experiences. Others have proposed that projects and partnerships between school and work institutions should be organized (e.g., Onstenk 2010; Tanggaard 2007). In addition to this, Wesselink et al. (2010) stress that teachers, students and workplace supervisors should explicate their different conceptions of and mutual responsibilities regarding workplace learning. Building on the relational approach taken by these authors, our study explicitly shows how school and work institutions can mutually feed the learning processes during apprenticeships. Whereas experiences in workplaces offer unique learning opportunities in participating in the socio-technical system of laboratory work, release days at school can be designed to enable discussion of and critical reflection on work experiences. As we have learned from talking to teachers, they themselves may be insecure about their disciplinary 
knowledge on the one hand, and the specifics of the many different labs on the other. Stimulating students to ask critical and reflective questions at labs could go along with accepting that they do not have to know everything, but that they can adopt the role of coach. This is especially relevant, as one cannot expect school to be continuously up to date with rapid technological changes and expensive machines.

From a boundary-crossing perspective this study has made a further step in conceptualizing school-work transitions, explicitly not as a matter of overcoming the differences between both socially and culturally shaped learning sites, but rather as a matter of creating continuity in actions and interactions between school institutes and local workplaces. Our empirical focus has been limited to challenges and learning opportunities at the level of individual students, with more detailed data from school than from the workplaces. On a broader level and in the longer term one can recognize how school and work are not static sites, but practices that are themselves in a process of development, as our interviews with teachers and supervisors confirmed. What is of interest then is to study whether and how school and work practices are also in a situation of mutual development, due to the actions and interactions taking place between the school institutes and local workplaces. One can imagine that student apprenticeships and communication about them between teachers and workplace supervisors, though initially favoring students' individual learning processes, can also lead to new insights and changes in school and work as practices (Konkola et al. 2007). In a literature review on boundary crossing (Akkerman and Bakker 2011a) we identified four learning mechanisms that can take place at practice level when actions and interactions across sites are established:

- identification (learning the particularities of both sites in relation to one another),

- coordination (establishing cooperative and routinized exchanges between practices),

- reflection (learning new things about the practice by taking on the perspective of the other practice),

- transformation (changing practices in response to one another or creating a new in-between practice).

A suggestion for further research is to investigate whether and how these four processes of mutual development of school and work practices take place and are dependent on each other (see Akkerman and Bakker 2011b). For such an investigation, it is important to arrange recordings of interactions not only at the school site, but also of interactions in the workplace between apprentices, supervisors, and other colleagues. Furthermore, this would require not only a micro perspective focused on (inter)actions of (groups of) people involved, but also an investigation of institutional and national developments regarding vocational education.

Open Access This article is distributed under the terms of the Creative Commons Attribution Noncommercial License which permits any noncommercial use, distribution, and reproduction in any medium, provided the original author(s) and source are credited. 


\section{References}

Akkerman, S. F., \& Bakker, A. (2011a). Boundary crossing and boundary objects. Review of Educational Research, 81, 132-169.

Akkerman, S. F., \& Bakker, A. (2011b). Learning at the boundary: An introduction. International Journal of Educational Research, 50(1), 1-5.

Akkerman, S. F., \& Meijer, P. C. (2011). A dialogical approach to conceptualizing teacher identity. Teaching and Teaching Education, 27, 208-319.

Bakker, A., Hoyles, C., Kent, P., \& Noss, R. (2006). Improving work processes by making the invisible visible. Journal of Education and Work, 19, 343-361.

Bakker, A., Kent, P., Noss, R., \& Hoyles, C. (2009). Alternative representations of statistical measures in computer tools to promote communication between employees in automotive manufacturing. Technology Innovations in Statistics Education, 3(2). http://www.escholarship.org/uc/item/53b9122r.

Bakker, A., Kent, P., Hoyles, C., \& Noss, R. (2011a). Designing for communication at work: a case for technology-enhanced boundary objects. International Journal of Educational Research, 50(1), 26-32.

Bakker, A., Wijers, M., Jonker, V., \& Akkerman, S. (2011b). The use, nature and purposes of measurement in intermediate-level occupations. ZDM International Journal of Mathematics Education, 43(5), 737-746. doi:10.1007/s11858-011-0328-3.

Biemans, H. J. A., Nieuwenhuis, A. F. M., Poell, R. F., Mulder, M., \& Wesselink, R. (2004). Competencebased VET in the Netherlands: backgrounds and pitfalls. Journal of Vocational Education and Training, 56(4), 523-538.

Billett, S. (2001). Learning in the workplace: Strategies for effective practice. Sydney: Allen \& Unwin.

Billett, S. (2010). Vocational learning: Contributions of workplaces and educational institutes. In R. Maclean \& D. Wilson (Eds.), International Handbook of Education for the Changing World of Work: Bridging Academic and Vocational Learning (pp. 1711-1723). Bonn, Germany: Springer Science.

Billett, S., \& Rose, J. (1997). Developing conceptual knowledge in the workplace. Australian Journal of Adult and Community Education, 37(1), 12-26.

Brown, J. S., Collins, A., \& Duguid, S. (1989). Situated cognition and the culture of learning. Educational Researcher, 18(1), 32-42.

Denzin, N. K., \& Lincoln, Y. S. (2000). Handbook of qualitative research (2nd ed.). Thousand Oaks: Sage Publications.

Detmar, B., \& de Vries, I. E. M. (2009). Beroepspraktijkvorming in het MBO: Ervaringen van leerbedrijven [Occupational preparation in MBO: Learning companies' experiences]. Amsterdam: Dijk12.

Edwards, A. (2011). Building common knowledge at the boundaries between professional practices: relational agency and relational expertise in systems of distributed expertise. International Journal of Educational Research, 50(1), 33-39.

Fillietaz, L., de Saint-Georges, I., \& Duc, B. (2010). Skiing, cheese fondue and Swiss watches: analogical discourse in vocational training interactions. Vocations and Learning, 3, 117-140.

Finch, C., Mulder, M., Attwell, G., Rauner, F., \& Streumer, J. (2007). International comparisons of schoolto-work transitions. European Education Research Association Journal, 3(2), 3-15.

Grant, G., Elbow, P., Ewens, T., Gamson, Z., Kohli, W., Neumann, W., Olesen, V., \& Riesman, D. (1979). On competence. A critical analysis of competence-based reforms in higher education. San Francisco: Jossey-Bass.

Griffiths, T., \& Guile, D. (2003). A connective model of learning: the implications for work process knowledge. European Educational Research Journal, 2(1), 56-73.

Guba, E. G. (1981). Criteria for assessing the trustworthiness of naturalistic inquiries. ECTJ Annual Review Paper, 29(2), 75-91.

Guile, D., \& Griffiths, T. (2001). Learning through work experience. Journal of Education and Work, 14, $113-131$.

Hardy, M., \& Parent, C. (2003). School-workplace collaboration: An uneasy partnership. Experiences from two alternation programs in Quebec. In H. G. Schuetze \& R. Sweet (Eds.), Integrating school and workplace learning in Canada. Principles and practices of alternation education and training (pp. 135-155). Montreal: McGill-Queens' University Press.

Harreveld, B., \& Singh, M. (2009). Contextualising learning at the education-training-work interface. Education and Training, 51(2), 92-107.

Hoyles, C., Noss, R., Kent, P., \& Bakker, A. (2010). Improving mathematics at work: The need for technomathematical literacies. London: Routledge. 
Hutchins, E. (1995). Cognition in the wild. Cambridge: MIT Press.

Knorr-Cetina, K. D. (1999). Epistemic cultures. How the sciences make knowledge. Cambridge: Harvard University Press.

Konkola, R., Tuomi-Gröhn, T., Lambert, P., \& Ludvigsen, S. (2007). Promoting learning and transfer between school and workplace. Journal of Education and Work, 20, 211-228.

Latour, B. (1999). Pandora's hope: Essays on the reality of science studies. Cambridge: Harvard University Press.

Lave, J. (1988). Cognition in practice: Mind, mathematics and culture in everyday life. New York: Cambridge University Press.

Lave, J. (2011). Apprenticeship in critical ethnographic practice. Chicago: University of Chicago Press.

Lave, J., \& Wenger, E. (1991). Situated learning: Legitimate peripheral participation. Cambridge: Cambridge University Press.

Nelen, A., Poortman, C. I., Grip, A. de, Nieuwenhuis, A. F. M., \& Kirschner, P. A. (2010). Het rendement van combinaties van leren en werken. Een review studie [The return on investment of combinations of learning and working. A review study].'s-Gravenhage, the Netherlands: NWO PROO.

Nunes, T. A., Schliemann, D., \& Carrahar, D. W. (1993). Street mathematics and school mathematics. Cambridge: Cambridge University Press.

Onstenk, J. (2010). Coaching and collaborative work-based learning in Dutch VET: The 'TEAMstages' project. In E. Smith \& F. Rauner (Eds.), Rediscovering apprenticeship: Research findings of the international network of innovative apprenticeship (INAP) (pp. 161-170). Dordrecht: Springer. doi:10.1007/978-90-481-3116-7 14.

Onstenk, J., \& Janmaat, H. (2006). Samen werken aan leren op de werkplek: Op weg naar co-design en co-makership van scholen en bedrijven [Cooperating for learning at the workplace: towards co-design and co-makership of schools and companies]. Den Bosch: Cinop EC.

Poortman, C. J. (2007). Workplace learning processes in senior secondary vocational education. Enschede: University of Twente.

Säljö, R. (2003). Epilogue: From transfer to boundary-crossing. In T. Tuomi-Gröhn \& Y. Engeström (Eds.), Between school and work. New perspectives on transfer and boundary-crossing (pp. 311321). Amsterdam: Pergamon.

Smith, J. P., III. (1999). Tracking the mathematics of automobile production: are schools failing to prepare students for work? American Education Research Journal, 36, 835-878.

Tanggaard, L. (2007). Learning at trade vocational school and learning at work: boundary crossing in apprentices' everyday life. Journal of Education and Work, 20, 453-466.

Toolsema, B., \& Nijhof, W. J. (2003). Rethinking competency from a labour market perspective. In F. Achtenhagen \& E. G. John (Eds.), Meilensteine der beruflichen Bildung (Band 3): Politische Perspektiven beruflicher Bildung (pp. 297-310). Bielefeld: W. Bertelsmann Verlag \& Co. KG.

Tuomi-Gröhn, T., Engeström, Y., \& Young, M. (2003). From transfer to boundary-crossing between school and work as a tool for developing vocational education: An introduction. In T. Tuomi-Gröhn \& Y. Engeström (Eds.), Between school and work. New perspectives on transfer and boundary-crossing (pp. 1-18). Amsterdam: Pergamon.

Wedege, T. (1999). To know or not to know - mathematics, that is a question of context. Educational Studies in Mathematics, 39, 205-227.

Wenger, E. (1998). Communities of practice, learning, meaning and identity. Cambridge, UK: Cambridge University Press.

Wesselink, R., de Jong, C., \& Biemans, H. J. A. (2010). Aspects of competence-based education as footholds to improve the connectivity between learning in school and in the workplace. Vocations and Learning, 3, 19-38.

Yin, R. K. (2009). Case study research: Design and methods. Thousand Oaks: SAGE Publications.

Sanne F. Akkerman is currently working as associate professor at the Department of Education of Utrecht University, Heidelberglaan 8, 3584 CS, Utrecht, The Netherlands; e-mail: s.f.akkerman@uu.nl. For the last 10 years she has been studying processes of boundary crossing and learning in various contexts, including interorganizational collaboration, intercultural communication, group diversity, school-work transitions, interdisciplinary science, and also considering at individual level the dialogical identity of students and professionals acting as brokers. 
Arthur Bakker is an assistant professor at the Freudenthal Institute for Science and Mathematics Education, Utrecht University, Princetonplein 5, 3584 CC, Utrecht, Netherlands; e-mail: a.bakker4@uu.nl. For several years he has been studying the development of techno-mathematical literacies in various workplaces and more recently has focused on vocational education and school-work transitions in particular. In his research he draws on sociocultural and cultural historical activity theories. 